\title{
Interaction of Infectious Viral Particles with a Quaternary Ammonium Chloride (QAC) Surface
}

\author{
I-Fu Tsao, Henry Y. Wang* \\ Department of Chemical Engineering, The University of Michigan, \\ Ann Arbor, Michigan 48109 \\ Charles Shipman, Jr. \\ Department of Biologic and Materials Sciences, The University of \\ Michigan, Ann Arbor, Michigan 48109
}

Accepted for publication November 4, 1988

The antiviral activity of a surface-bonded quaternary ammonium chloride (OAC) was examined in this study. The mechanism of inactivation was elucidated by a combination of infectivity assay, radioactive labeling assay, and sedimentation analysis. Although the virions are still infectious when attached onto the chemically modified surface, we found these viruses are inactivated if they are eluted from the surface. The inactivation is caused by the disruption of the viral envelope with subsequent release of the nucleocapsid. No evidence indicates the released nucleocapsid is further disrupted. An enveloped virus shows a much higher affinity for the QAC-treated surface than a nonenveloped one due to hydrophobic interaction. The QAC-treated beads can effectively remove the enveloped viruses at low protein concentrations. The titer of herpes simplex virus was reduced by a factor of nearly 5 logarithm units in a 0.5 wt $\%$ bovine serum albumin solution with less that $10 \%$ protein loss. However, the presence of proteins in the solution reduced both the rate and capacity of this nonspecific adsorption-inactivation process. As a consequence, the removal efficiency is relatively poor in solutions with high protein content.

\section{INTRODUCTION}

Quaternary ammonium chlorides (QAC) are cationic surface-active agents with antimicrobial activity. ${ }^{1,2}$ The major mode of action of QAC was identified as the cytolytic damage caused by its effects on cellular permeability. ${ }^{3}$ The virucidal capacity of a QAC-Zephiran (alkyl-dimethylbenzylammonium chloride) against various types of viruses was summarized by Klein and Deforest. ${ }^{4}$ They reported that Zephiran can effectively inactivate lipid-containing viruses like vaccinia virus, some nonlipid viruses such as reovirus, and bacteriophages but is not effective against smaller nonlipid viruses such as picornaviruses. QAC display their antimicrobial activity even after being covalently immobilized on inert supports because

\footnotetext{
* To whom all correspondence should be addressed
}

they can act on the membranes of various cells. The effects of surface-bonded organosilicon QAC on bacteria, yeast, fungi, and algaes have been the topic of several papers. ${ }^{3,5,6-8}$ The antimicrobial activity of immobilized QAC is not due to leaching of the compound since the radiotracer study by Isquith ${ }^{3}$ showed no leakage of the immobilized QAC from the surface. Our own cytotoxicity tests also confirmed this point. However, the antiviral activity of these immobilized compounds has not been investigated previously.

In the current study, we have demonstrated the efficacy of QAC-treated surfaces to remove an enveloped virus, herpes simplex virus type-1, in aqueous solutions with and without the presence of proteins. Experiments have further demonstrated that the viruses were inactivated. The mechanism that underlies this inactivation is elucidated by using doubled-labeled HSV-1.

\section{MATERIALS AND METHODS}

\section{Chemicals}

3-(Trimethoxysilyl)propyldimethyloctadecyl ammonium chloride (Si-QAC), Dow Corning 5700 antimicrobial agent, was provided by W. Curtis White (Dow Corning, Midland, MI). It is a methanolic solution containing $42 \mathrm{wt} \%$ of this active ingredient. [Methyl ${ }^{3} \mathrm{H}$ ] thymidine (20 Ci $/ \mathrm{mmol})$, [methyl ${ }^{14} \mathrm{C}$ ] thymidine $(58 \mathrm{mCi} / \mathrm{mmol})$, and $\left[2{ }^{3} \mathrm{H}\right]$ mannose $(25 \mathrm{Ci} / \mathrm{mmol})$ were purchased from New England Nuclear (Boston, MA). Other chemicals were of reagent grade and were purchased from various commericial sources.

\section{Preparation of Adsorbent}

Dried alginate-magnetite beads (Fig. 1) were prepared by a method modified from that described by Burns et al. 


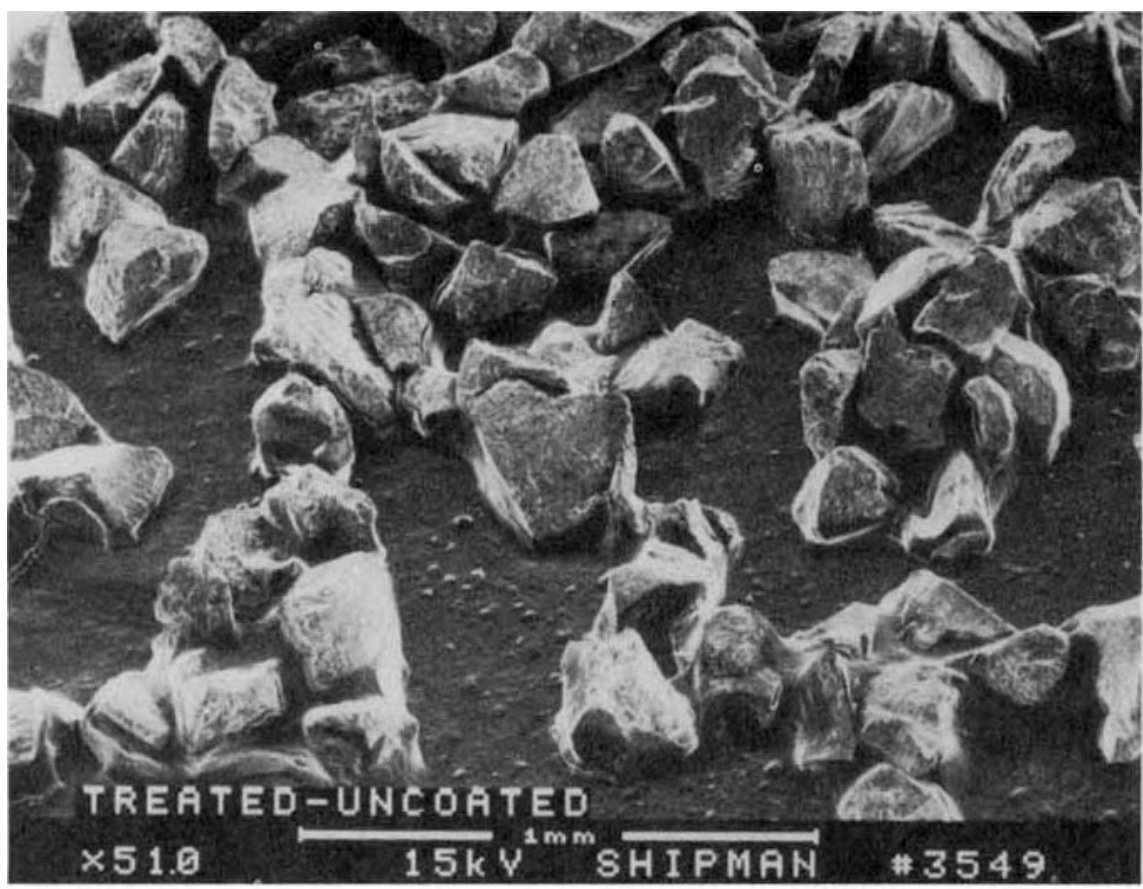

Figure 1. Scanning electron micrograph of the QAC-treated beads.

with the following modifications. ${ }^{9}$ Barium chloride was used as a gel-inducing agent for better stability. ${ }^{10}$ The beads were further stabilized by treating with glutaraldehyde in the presence of polyethyleneimine to avoid dissolution. ${ }^{11}$ In brief, the alginate-magnetite gel spheres were suspended in $0.5 \%(\mathrm{w} / \mathrm{v})$ polyethyleneimine $-\mathrm{HCl}$ in $50 \mathrm{mM} \mathrm{CaCl} 2$ (pH 7.0) for $24 \mathrm{~h}$ at room temperature with stirring. The gel spheres were washed briefly with $\mathrm{H}_{2} \mathrm{O}$ and subsequently incubated in $1 \%(\mathrm{v} / \mathrm{v})$ glutaraldehyde, $10 \mathrm{~m} M$ sodium phosphate $(\mathrm{pH} 7.0)$ at room temperature for 1 min with stirring. To remove or "neutralize" the unreacted glutaraldehyde molecules, the gel spheres were washed 3 times with $\mathrm{H}_{2} \mathrm{O}$ and incubated with $1 M$ glycine (pH 7.0) for $30 \mathrm{~min}$ so that glutaraldehyde does not leach out from the beads. The treated preparation was washed in $\mathrm{H}_{2} \mathrm{O}$ and stored at $4^{\circ} \mathrm{C}$ until the drying step. Dried beads with diameters between 0.15 and $0.25 \mathrm{~mm}$ were obtained by crushing the original spherical beads. A $1 \%$ solution of Si-QAC was prepared by diluting the stock solution in distilled water at $\mathrm{pH} 5$. After the beads were added to the Si-QAC solution, the reaction temperature was raised to about $50^{\circ} \mathrm{C}$ for $10 \mathrm{~min}$. The $\mathrm{pH}$ was adjusted to 10.5 , and reaction continued for an additional $10 \mathrm{~min}$. The beads were dried in an oven $\left(100^{\circ} \mathrm{C}\right)$, rinsed several times with sterile deionized water $(\mathrm{pH} 7.0)$, and stored at $4^{\circ} \mathrm{C}$.

\section{Cell Culture}

BSC-1 cells (an established line of African green monkey kidney cells) were grown as a monolayer in minimal essential medium (MEM) with Earle's salts supplemented with $10 \%$ fetal bovine serum (FBS) and $1.1 \mathrm{~g} / \mathrm{L}$ sodium bicarbonate. Cells were passaged according to conven- tional procedures by using $0.05 \%$ trypsin plus $0.02 \%$ ethylenediaminetetraacetic acid (EDTA) in HEPES-buffered balanced saline (HBS) ${ }^{12}$ Tissue culture flasks were incubated at $37^{\circ} \mathrm{C}$ in a humidified $3 \% \mathrm{CO}_{2}-97 \%$ air atmosphere. Total cell counts were made using a Coulter counter equipped with a $100-\mu \mathrm{m}$ orifice.

\section{Virus and Plaque Assay}

HSV-1 strain 148 was passaged in KB cells to prepare virus stocks of high titer $\left(10^{8}-10^{9} \mathrm{PFU} / \mathrm{ml}\right)$ as described previously. ${ }^{13}$ HSV-1 was assayed by using monolayer cultures of BSC-1 cells grown in six-well cluster dishes. The cells were planted $3 \times 10^{5}$ cells/well in $\operatorname{MEM}(E)$ with $10 \%$ FBS and $1.1 \mathrm{~g} / \mathrm{L}$ sodium bicarbonate. After $24 \mathrm{~h}$ the cell sheet was about $80 \%$ confluent and was inoculated with $0.2 \mathrm{~mL}$ virus suspension to be assayed and incubated for $1 \mathrm{~h}$ to permit viral adsorption. The cells were then overlaid with $3 \mathrm{~mL}$ medium containing $0.5 \%$ methocel $(4000 \mathrm{cP})$ (Dow Chemical Midland, MI) incubated for another 2 days. After aspiration of the overlay, the cells were fixed and stained with crystal violet in $20 \%$ methanol, and the macroscopic plaques were enumerated.

\section{Preparation of Labeled Virus}

HSV-1 with $\left[{ }^{3} \mathrm{H}\right]$-labeled DNA was prepared using $\left[{ }^{3} \mathrm{H}\right]$ thymidine by a method similar to the one described previously. ${ }^{14}$ Monolayers of KB cells in $150-\mathrm{cm}^{2}$ tissue culture flasks were grown to $80 \%$ confluence and then infected with HSV-1 (multiplicity of infection, M.O.I. $=20$ ) in virus growth medium [VGM, MEM(E) with $0.127 \mathrm{~g} / \mathrm{L}$ L-arginine, buffered with $25 \mathrm{~m} M$ HEPES, $\mathrm{pH} 7.4$, at $22^{\circ} \mathrm{C}$ 
and supplemented with 10\% FBS]. Virus (M.O.I. $=0.1$ ) was allowed to adsorb for $1 \mathrm{~h}$ at $37^{\circ} \mathrm{C}$. Then each monolayer was rinsed twice with warm VGM without serum to remove unadsorbed viruses. Thirty milliliters of VGM was added to each flask for an additional $2 \mathrm{~h}$ incubation. The $\left[{ }^{3} \mathrm{H}\right]$ thymidine was added to give a concentration of $17 \mu \mathrm{Ci} / \mathrm{mL}$ in each flask, and the incubation was continued for $36 \mathrm{~h}$ to permit maximum production of supernatant virus. The radioactive suspension was then briefly sonicated and centrifuged at a low speed to remove cells and cell debris. The supernatant fluid was further centrifuged using a Beckman JA-21 rotor at $18,000 \mathrm{~g}$ for $20 \mathrm{~min}$ at $4^{\circ} \mathrm{C}$ in a Beckman J-21 preparative centrifuge to pellet mature virions. The virus was resuspended in a small volume of medium [MEM(E) with 5\% FBS], then further purified by sedimentation through $5-25 \%$ sucrose with a $45 \%$ sucrose cushion in a SW 50.1 rotor at $150,000 \mathrm{~g}$ for $1 \mathrm{~h}$ in a Beckman L3-50 ultracentrifuge. The band of labeled virus was collected and dialyzed against $\mathrm{HBS}$ at $4^{\circ} \mathrm{C}$. The virus was pelleted using a JA-21 rotor as described above and resuspended in $\operatorname{MEM}(E)$ with 5\% FBS. The final preparations were stored at $-76^{\circ} \mathrm{C}$ until retrieved. The double-labeled $\left(\left[{ }^{3} \mathrm{H}\right]\right.$ and $\left.\left[{ }^{14} \mathrm{C}\right]\right) \mathrm{HSV}-1$ was prepared by the same procedure described above except that [methyl- $\left.{ }^{14} \mathrm{C}\right]$ thymidine $(10 \mu \mathrm{Ci} / \mathrm{mL})$ and $\left[2{ }^{3} \mathrm{H}\right]$ mannose $(7 \mu \mathrm{Ci} / \mathrm{mL})$ were used to label viral nucleocapsid and envelope, respectively. The $\left[2{ }^{3} \mathrm{H}\right]$ mannose is commonly used as a specific viral envelope glycoprotein label as described by Eisenberg et al. ${ }^{15}$ To facilitate the uptake of $\left[2-{ }^{3} \mathrm{H}\right]$ mannose by the cells, glucose-free Dulbecco's modified Eagle's medium with $350 \mathrm{mg} / \mathrm{L} \mathrm{L-glutamine}$ and $110 \mathrm{mg} / \mathrm{L}$ sodium pyruvate was used for the preparation of VGM.

\section{Protein Assay}

Samples collected in all experiments were cooled and stored at $4^{\circ} \mathrm{C}$. The concentration of total protein in the solution was assayed by the method of Bradford. ${ }^{16}$

\section{Batch Adsorption Experiments}

During these experiments, adsorbents and viruses were continuously mixed in vials by a tube rocker $(30$ cycles $/ \mathrm{s}$ ) at room temperature. To prevent virus adsorption onto vial walls, the vials were filled with 5\% BSA in HBS for 30 min and air dried after discarding the BSA solutions to coat the inner surfaces. Reaction mixtures of known composition were made by adding the stock solution to HBS at $\mathrm{pH}$ 7.0. A solution of $0.5 \%$ BSA in HBS was used in all experiments unless otherwise stated. All stock chemical solutions were filter sterilized and stored at $4^{\circ} \mathrm{C}$.

In the equilibrium studies of virus adsorption, the time required to reach equilibrium was determined by periodically sampling over a $24-\mathrm{h}$ period. In the kinetic studies, samples were withdrawn at predetermined time intervals and assayed for virus titers. Each adsorption experiment was performed at least twice and the averaged results were presented.

\section{Mechanistic Study of Virus Inactivation}

The experimental scheme in Figure 2 was designed to elucidate the mechanism of HSV-1 inactivation on a QACtreated surface. The $\left[{ }^{3} \mathrm{H}\right]$-labeled HSV-1 was used in this experiment. The "control vial" contained the virus suspension without adsorbent while the "reaction vial" had 10 wt \% QAC-treated beads. Both vials were shaken gently $(30 \mathrm{cycles} / \mathrm{s})$ at room temperature for $2 \mathrm{~h}$. Then the first set of samples were collected from the supernatant of both vials and saved for the assays of infectivity and radioactivity. Sedimentation analysis also was carried out. Elution was subsequently performed at room temperature for 1 $\mathrm{h}$ by directly adding $4 \times$ strength eluant ( $1 \%$ tryptone, $10 \%$ FBS, and $1 M$ glycine) to the suspension as described by Murray and Laband. ${ }^{17}$ The second set of samples from both vials was collected and assays were performed accordingly. Although little variation was observed in replicate experiments, values were obtained in two trials and represent the means of four determinations.

\section{Sedimentation Analysis of Labeled Virus}

Changes in the sedimentation profiles of the radioactively labeled HSV-1 by the adsorption and elution steps were determined by rate-zonal centrifugation. ${ }^{18}$ Virus suspension $(0.4 \mathrm{~mL})$ was layered onto a $5-45 \%$ sucrose gradient in HBS. Centrifugation was carried out using a SW 50.1 swing-out rotor at $150,000 \mathrm{~g}$ for $45 \mathrm{~min}$ at $4^{\circ} \mathrm{C}$ in a Beckman model L3-50 ultracentrifuge, and fractions collected from the bottom of the gradient were analyzed for total radioactivity in scintillation cocktail. Counts per minute were determined in a Beckman LS 8100-Texas In-

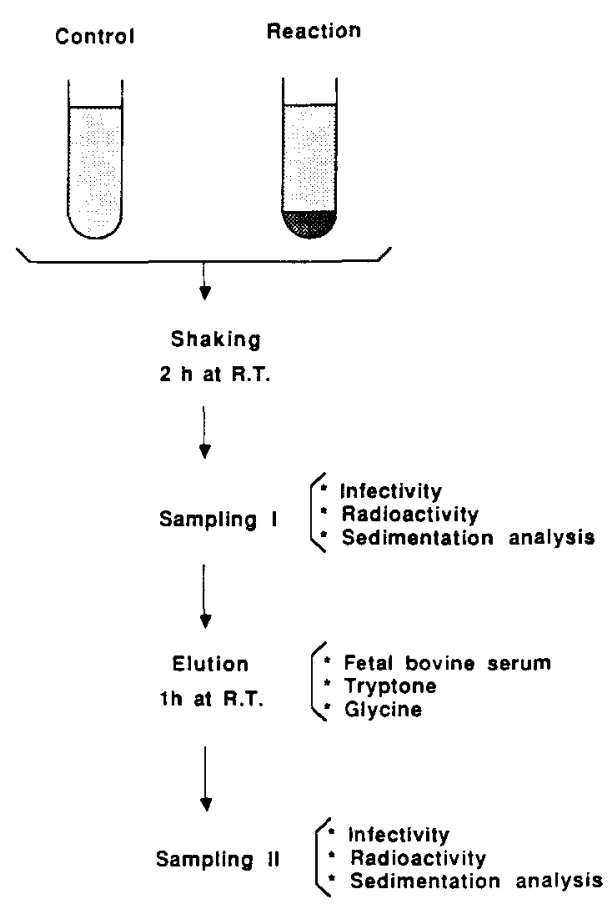

Figure 2. Experimental scheme for the mechanistic study of virus inactivation using QAC-treated beads. 
struments 733 liquid scintillation spectrometer system. For samples with $\left[{ }^{3} \mathrm{H}\right]$ and $\left[{ }^{14} \mathrm{C}\right]$ double labeling, standard calibration was run to subtract $\left[{ }^{14} \mathrm{C}\right]$ spillover radioactivity in $\left[{ }^{3} \mathrm{H}\right]$ counting window.

\section{RESULTS}

\section{Effect of Protein Concentration on HSV-1 Adsorption to QAC-Treated Beads}

Using the experimental procedure described above, we showed the QAC-treated beads were able remove HSV-1 effectively even in the presence of $0.5 \%$ BSA by weight (Fig. 3). The virus titer, starting from $1.0 \times 10^{7} \mathrm{PFU} / \mathrm{mL}$, dropped down more than $1 \log$ in the first $5 \mathrm{~min}$, was further reduced to $2.0 \times 10^{2} \mathrm{PFU} / \mathrm{mL}$, then leveled off. The total titer reduction was close to 5 logs. On the other hand, the protein recovery was more than $90 \%$. A parallel experiment using dried alginate-magnetite beads without QAC treatment showed that the titer reduction was only $8 \%$. Hence, neither untreated beads nor thermal inactivation was the major cause of the observed 5-log titer reduction. In addition, the $\mathrm{pH}$ of adsorption medium $(0.5 \%$ BSA in HBS) did not change throughout the experiment. As expected, BSA molecules compete with the viruses for the surface-binding sites. The binding capacity of the QACtreated beads was decreased with increased BSA concentration (Fig. 4). The titer reduction was close to $5 \operatorname{logs}$ for 0 and $0.5 \%$ BSA, 2 logs for $1 \%$ BSA, and only $1 \log$ for $4 \%$ BSA. Presumably the rate of BSA binding to the surface is higher as the concentration is increased. These results suggest that the QAC-treated bead is a very effective virus adsorbent at low protein concentrations. However, the titer reduction at high protein concentrations is poor due to the competitive binding of protein molecules.

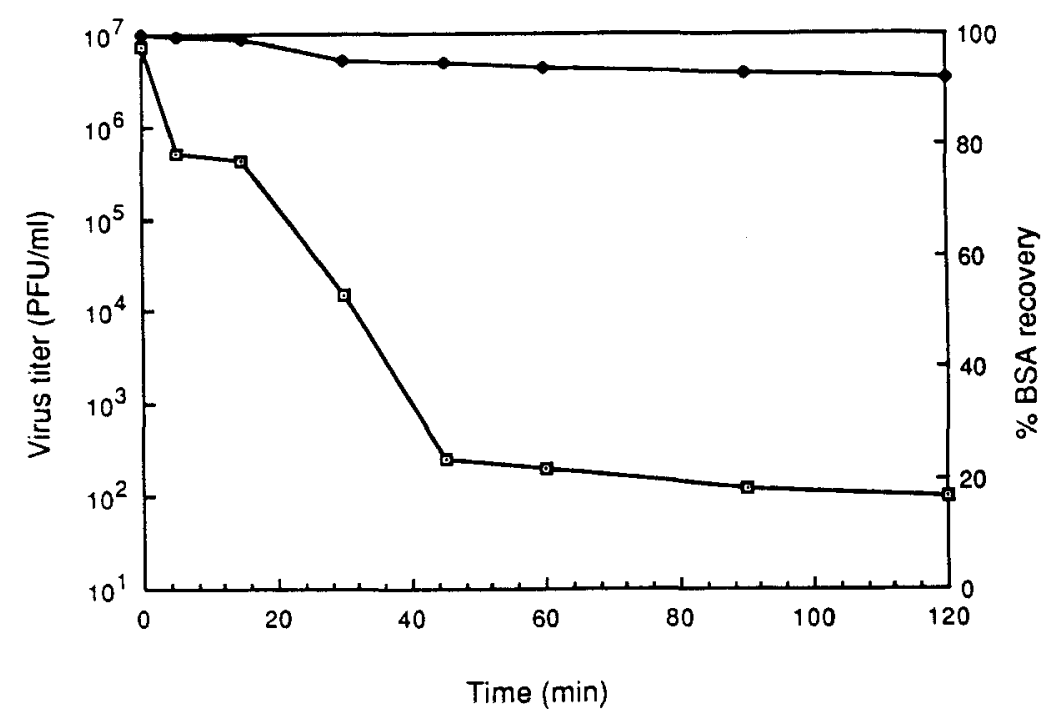

Figure 3. Effect of batch adsorption on HSV-1 titer reduction and BSA recovery using QAC-treated beads. Samples from the supernatant were assayed for virus titer $(\square)$ and BSA concentration $(\bullet)$. The initial BSA concentration was $0.5 \%$.

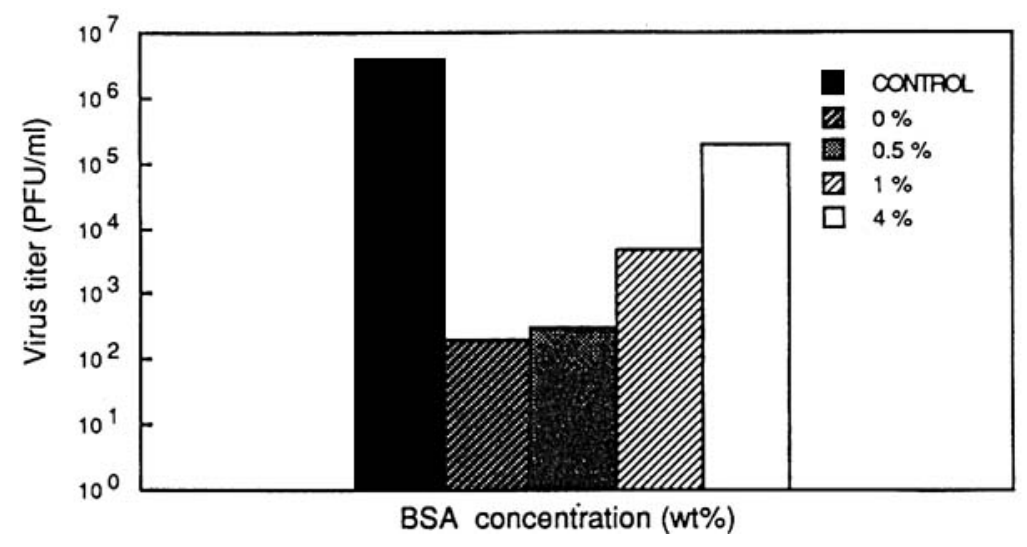

Figure 4. Effect of BSA concentration on HSV-1 titer reduction using QACtreated bead. Control was the virus suspension containing no adsorbent. Batch adsorption experiments were carried out in solutions of various BSA concentrations for $2 \mathrm{~h}$ at room temperature with $10 \%$ QAC-treated bead. 


\section{Comparative Recovery of HSV-1 Infectivity and Radioactivity During Adsorption and Elution Steps}

Data from sampling I and sampling II in Figure 2 were examined to compare the recovery of infectivity and radioactivity of the viruses in various stages of the experiment. Figure 5(a) shows the effects of adsorption and elution on the HSV-1 infectivity. The virus suspension was mixed with $10 \%$ by weight QAC-treated beads and gently shaken for $2 \mathrm{~h}$ at room temperature. The HSV-1 titer reduction was more than 4 logs. However, the elution experiments indicated that almost all the lost infectivity cannot be recovered. For the same set of samples, the effects of adsorption and elution on HSV-1 radioactivity are illustrated in Figure 5(b), which shows the results from samples of parallel experiments with $1: 2$ dilutions of initial virus titer. The radioactivity of the virus suspensions were consistently reduced by only $40 \%$ of the original value while the elution step recovered about half of the adsorbed radioactivity. In other words, the specific infectivity of virus in the suspensions was reduced drastically by the adsorption and elution steps.

\section{Effects of Adsorption and Elution on Sedimentation Behaviors of Virus Suspensions}

To elucidate the mechanism of enveloped virus inactivation on QAC-treated surface, double-labeled HSV-1 (with $\left[{ }^{3} \mathrm{H}\right]$ in the envelope only and $\left[{ }^{14} \mathrm{C}\right]$ in the nucleocapsid only) was used in adsorption-elution experiments. The sedimentation behaviors of the viral particles were examined by centrifugation through $5-45 \%$ sucrose gradient. Since it is a rate-zonal centrifugation, the resolution of particles is based mainly on size difference. Figure 6(a) shows the sedimentation profiles, both $\left[{ }^{3} \mathrm{H}\right]$ and $\left[{ }^{14} \mathrm{C}\right]$, of the virus suspension in which no adsorbent was added (control). There are two peaks appearing in the $\left[{ }^{14} \mathrm{C}\right]$ profile of the control, whereas there is only one in the $\left[{ }^{3} \mathrm{H}\right]$ profile. Notice that the first peak (from the bottom) of the $\left[{ }^{14} \mathrm{C}\right]$ profile coincides with the only peak in the $\left[{ }^{3} \mathrm{H}\right]$ profile. That is, evidently, the particles in the second peak of the $\left[{ }^{14} \mathrm{C}\right]$ profile do not contain $\left[{ }^{3} \mathrm{H}\right]$-labeled viral particles. In addition, based on the fact that bigger particles settle faster than smaller ones as well as the infectivity assay results of each fraction [Fig. 6(a), inset], we determined that the viral particles in the first peak of the $\left[{ }^{14} \mathrm{C}\right]$ profile are infectious virions of HSV-1 (180 nm diameter) while the ones in the second peak are noninfectious nucleocapsids of HSV-1 (105 $\mathrm{nm}$ diameter). The possible virus aggregates would stay in the leading region of the first peak (i.e., above $45 \%$ sucrose). Two points can be made by comparing the sedimentation profiles of the control [Fig. 6(a)] and that of the reaction [Fig. 6(b)]. First, the first peak of the $\left[{ }^{14} \mathrm{C}\right]$ profile and the only peak of the $\left[{ }^{3} \mathrm{H}\right]$ profile were almost totally eliminated. Second, the viral particles in the second peak of the $\left[{ }^{14} \mathrm{C}\right]$ profile were enriched. These results suggest that nearly all the enveloped virus particles were adsorbed by the QAC-treated beads as indicated also
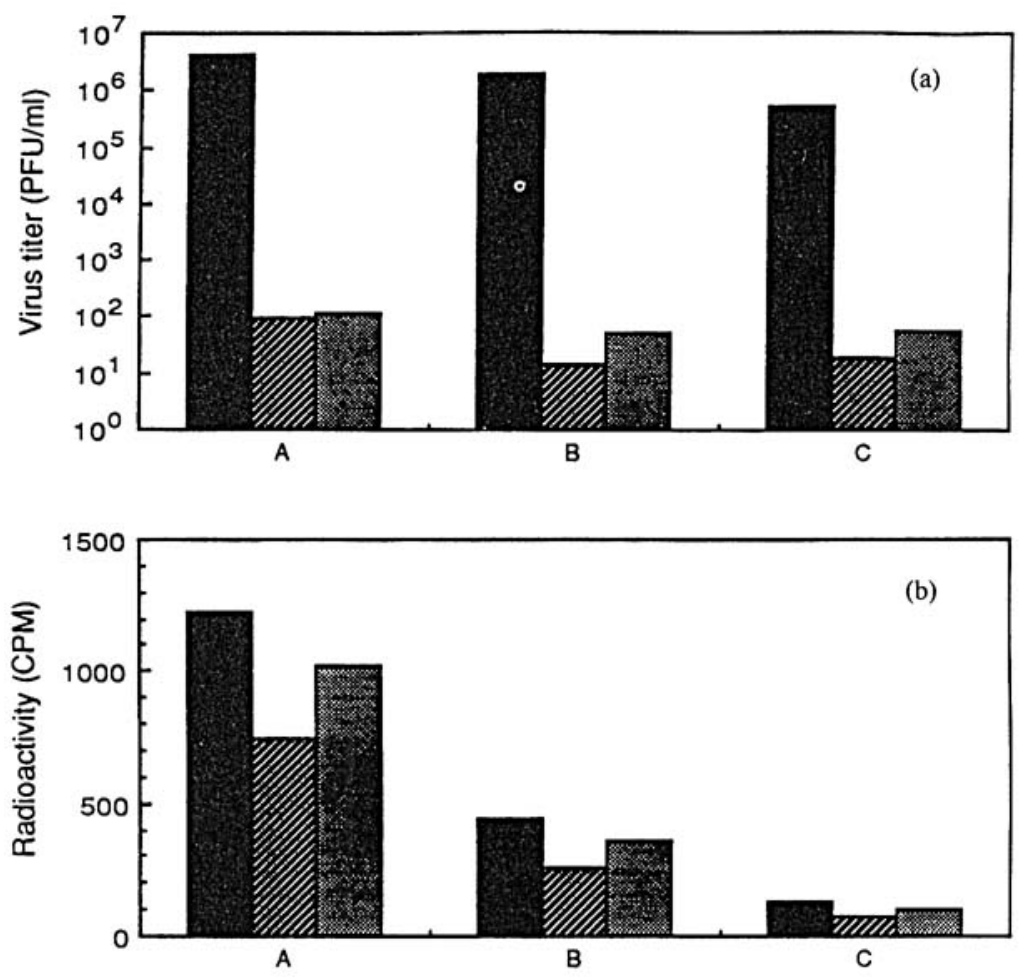

Figure 5. Comparative recovery of HSV-1 (a) infectivity and (b) radioactivity in various stages of the mechanistic study. $A, B$, and $C$ were samples of parallel experiments with $1: 2$ dilution. The measurements of the control $(\mathbf{E})$ that contains no adsorbent was compared with those of samples after adsorption $(\mathbb{Z})$ and after elution (⿴囗玉 $)$. 

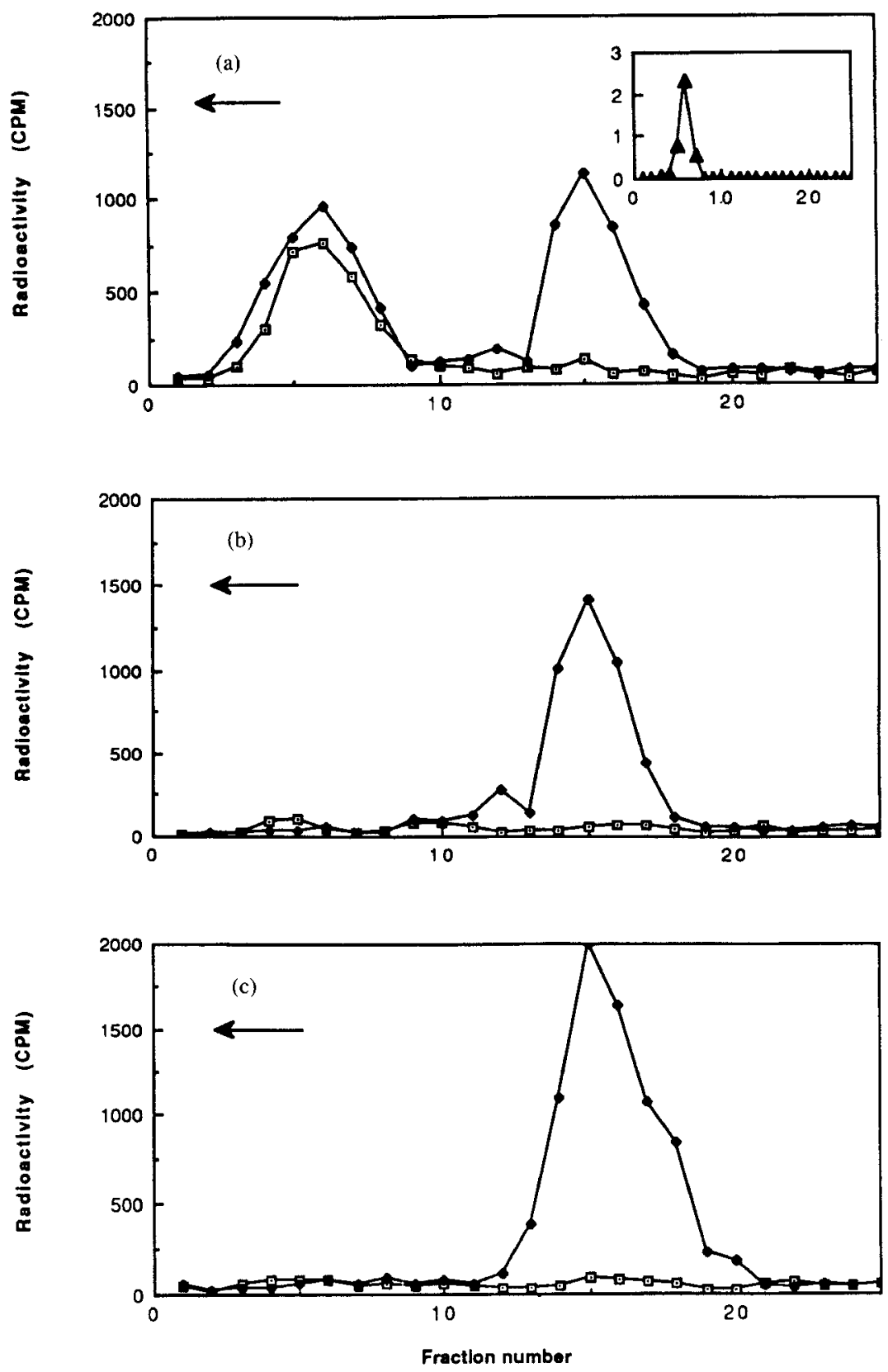

Figure 6. Effect of adsorption and elution on the sedimentation behaviors of doublelabeled HSV-1 particles. Samples were analyzed by sedimentation in gradients ( $5 \%$ to $45 \%$ sucrose, SW $50.1,150,000 \times \mathrm{g}, 45 \mathrm{~min}, 4^{\circ} \mathrm{C}$ ). The arrows show the direction of sedimentation. The $\left[{ }^{14} \mathrm{C}\right](\bullet)$ and $\left[{ }^{3} \mathrm{H}\right](\square)$ profiles in (a) are the control containing no adsorbent; the corresponding virus titer $\left(\mathrm{PFU} / \mathrm{ml} \times 10^{7}\right)$ in each fraction $(\Lambda)$ is shown in the inset. The sedimentation profiles of viral particles from sample I (after adsorption) and sample II (after elution) in Fig. 2 are shown in (b) and (c), respectively.

by the results of the infectivity assay [5-log titer reduction, as shown in Fig. 5(a)]. Furthermore, a portion of the $\left[{ }^{14} \mathrm{C}\right]$ radioactivity carried by the viral DNA in the bulk solution can be attributed to the release of the nucleocapsids. The latter statement was proven by the elution experiment, which demonstrated the eluted viral particles were apparently noninfectious nucleocapsids [Fig. 6(c)]. We also analyzed the sedimentation profiles of the beads washed with HBS before the elution step. It was found that the profiles were very similar to Figure 6(c) with only one peak in the $\left[{ }^{14} \mathrm{C}\right]$ profile at around fraction 15 . The $\left[{ }^{3} \mathrm{H}\right]$ radioactivities are very low in all fractions of Figures 6(b) and (c). This suggests that the envelope membrane of HSV-1 was tightly adsorbed by the QAC-treated surface, which is highly hydrophobic.

\section{Infectivity of HSV-1 Adsorbed on QAC-Treated Surface}

To investigate whether the virus particles were still infectious when they are adsorbed on the QAC-treated surface, we washed the beads taken out right after the 


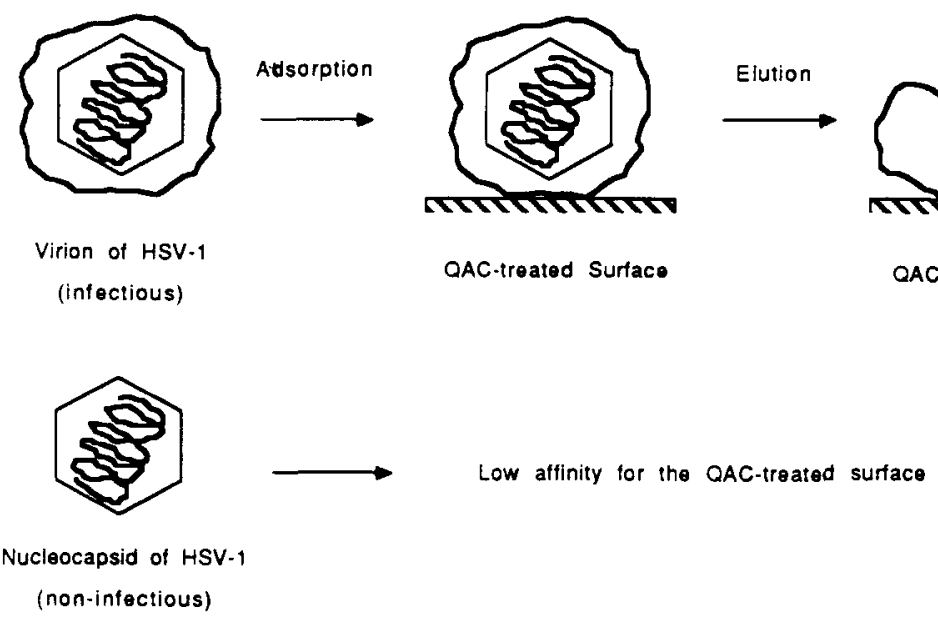

Figure 7. Proposed mechanism of HSV-1 inactivation on QAC-treated surface. The inactivation is caused by the disruption of the viral envelope with subsequent release of the nucleocapsid.

adsorption step and incubated them with a monolayer of BSC-1 cell. Plaques resulting from virus infection were formed surrounding all the beads tested. The plaques are not caused by the bead's movement as suggested by a control experiment using fresh QAC-treated beads without adsorbed viruses. However, it is possible that only a small fraction of the adsorbed viruses remain infectious.

\section{DISCUSSION}

These results demonstrate the ability of the QAC-treated surface to adsorb HSV-1, an enveloped virus, under various processing conditions. Hydrophobic and electrostatic interactions are the predominating forces which effect the adsorption of microorganisms to a QAC-treated surface. ${ }^{3,5,6-8}$ For enveloped viruses, the hydrophobic interaction is presumably the major one since nonenveloped viruses show much lower affinity for the QAC-treated surface (unpublished data). The interactive effects of $\mathrm{pH}$, ionic strength, and temperature on the virus adsorption are currently under study in our laboratory.

Based on the observation that virus retains its infectivity when adsorbed on a QAC-treated surface together with the results from infectivity and radioactivity assays as well as the sedimentation analysis, we were able to derive the following mechanism of inactivation of HSV-1 on the QACtreated surface (Fig. 7). The mechanistic study indicates that HSV-1 was inactivated by the QAC-treated surface by virtue of the disruption of the viral envelope. This damage leads to an irreversible loss of infectivity. None of the evidence indicates that the released nucleocapsids are further disrupted. The virions of HSV-1 are readily adsorbed by the QAC-treated surface due to strong hydrophobic and other interactions. For the adsorbed virions, the part of envelope that is not in contact with the QAC-treated surface is still intact. The nucleocapsid can penetrate into a host cell by fusing the intact part of the envelope with the cell plasma membrane. The viral envelopes are disrupted when the elution is employed and hence only the nucleocapsids are released. The nucleocapsid shows a much lower affinity for the QAC-treated surface.

The QAC-treated bead made of dried alginate and magnetite used in this study is nonporous. To remove the viral contaminants from a protein solution, adsorbents of a nonporous nature are preferred in order to eliminate nonspecific adsorptions of desired proteins onto an intraporous surface.

Despite the fact that the diffusion coefficient of BSA is one order of magnitude higher than that of HSV-1, the adsorption rate of HSV-1 onto the QAC-treated surface is greater than that of the BSA. This result indicates that surface reaction, instead of diffusion, is the controlling step of the binding process. HSV-1 can readily bind to the QAC-treated surface simply because the viral envelope is hydrophobic in nature. The kinetic study indicates that HSV-1 was adsorbed/inactivated rapidly in the first hour following approximately a first-order reaction kinetics with respect to the remaining virus concentration in the solution. The leveling off of titer reduction is probably due to the effect of steric hindrance from previously adsorbed viruses and proteins. It has been shown that the residual virus titer can be completely eliminated by adding additional fresh beads to the suspension.

The significant reduction of virus adsorption capacity in solutions with high BSA concentration (more than 1\%) reflects the difficulty involved in the use of the QAC-treated beads to remove viruses from solutions with high protein contents such as plasma and serum. In this case, the use of affinity adsorbents based on specific interactions such as antibodies or cellular receptors appears to be more appropriate. Even so, QAC-treated beads certainly can find wide applications in treating blood products that have low protein content in solution, such as packed red blood cell and platelet concentrate. In order to avoid the possible damage caused by direct contact, however, a porous membrane barrier that allows free passage of viruses should be used to exclude the entry of cells.

We acknowledge partial financial support from the National Science Foundation. 


\section{References}

1. A. N. Petrocci, in Disinfection, Sterilization and Preservation, 3rd ed., S. S. Block, Ed. (Lea \& Febiger, Philadelphia, 1983), p. 309.

2. W. B. Hugo, J. Appl. Bacteriol., 30, 27 (1967).

3. A. J. Isquith, E. A. Abbott, and P. A. Waters, Appl. Environ. Microbiol., 24, 859 (1972).

4. M. Klein and A. Deforest, in Disinfection, Sterilization and Preservation, 3rd ed., S. S. Block, Ed. (Lea \& Febiger, Philadelphia, 1983), p. 422.

5. P. A. Walters, E. A. Abbott, and A. J. Isquith, Appl. Environ. Microbiol., 25, 253 (1972).

6. A. J. Isquith and C. J. McCollum, App. Environ. Microbiol., 36, 700 (1978).

7. J. L. Speier and J. R. Malek, J. Coll. Interf. Sci., 89, 68 (1981).

8. Y. Nakagawa, H. Hayashi, T. Tawaratani, H. Kourai, T. Horie, and I. Shibasaki, Appl. Environ. Microbiol., 47, 513 (1983).
9. M. Burns, G. I. Kvesitadze, and D. Graves, Biotechnol. Bioeng., 27, 137 (1985).

10. F. Paul and P. M. Vignais, Enz. Microb. Technol., 2, 281 (1980).

11. S. Birnbaum, R. Pendleton, P-O. Larsson, and K. Mosbach, Biotech. Lett., 3, 393 (1982).

12. C. Shipman, Jr., Proc. Soc. Exp. Biol. Med., 130, 305 (1969).

13. C. Shipman, Jr., S. H. Smith, R. H. Carlson, and J. C. Drach, Agent Chemother., 9, 120 (1976).

14. J. C. Pelling, J. C. Drach, and C. Shipman, Jr., Virology, 109, 323 (1981).

15. R. J. Eisenberg, C. Hydrean-Stern, and G. H. Cohen., J. Virol., 31, 608 (1979).

16. M. Bradford, Anal. Biochem., 72, 248 (1985).

17. J.P. Murray and S. J. Laband, Appl. Environ. Microbiol., 37, 480 (1979). 